\title{
Association between failure in otoacoustic emissions and risk indicator for hearing loss
}

\author{
Kátia de Cássia Botasso ${ }^{1}$ \\ https://orcid.org/0000-0001-9746-0617 \\ Maria Cecília Pinheiro Marconi Lima² \\ https://orcid.org/0000-0002-4203-0019 \\ Carlos Roberto Silveira Correa ${ }^{1}$ \\ https://orcid.org/0000-0002-9232-2263
}

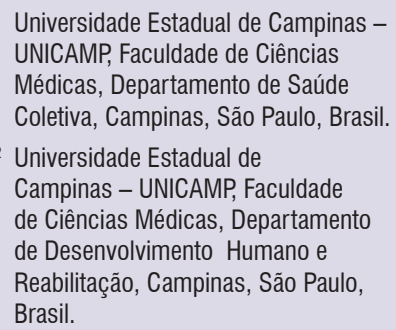

Conflict of interests: Nonexistent

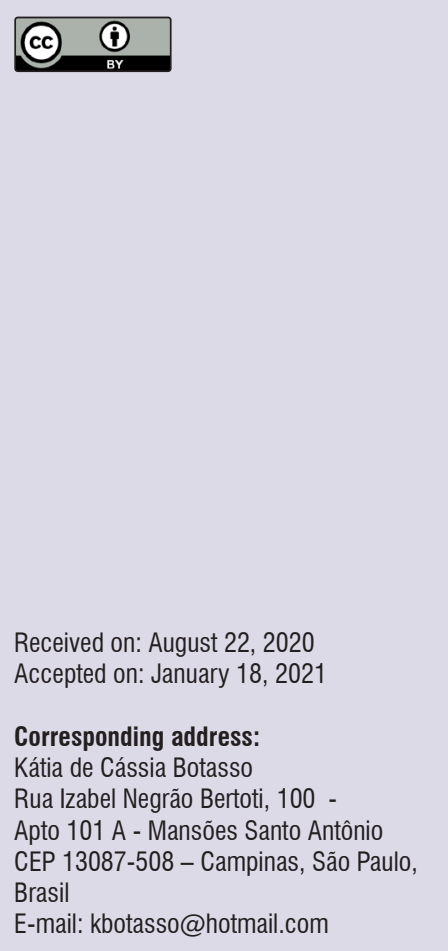

\section{ABSTRACT}

Purpose: to describe the results of a neonatal hearing health program and verify whether there is an association between the presence of risk indicators for hearing loss and failure in the tests and diagnosis.

Methods: a one-cohort, observational, retrospective study with secondary data contained in a spreadsheet concerning the family's sociodemographic condition, clinical history, and examination results of 7,800 participants who were submitted to hearing screening between 2010 and 2016. Absolute frequency and percentages were used in the description of the first and second stages. In the association between risk indicators and failures in the otoacoustic emissions, the odds ratio, confidence interval, and significance level at $0.5 \%$ were used.

Results: the risk indicators in 8 out of the 12 infants presented with hearing loss were ototoxic medication and intensive care unit (ICU) stay, whereas the likelihood of failure in the otoacoustic emissions occurred along with 11 indicators. The likelihood of a diagnosis of hearing loss was 13 times greater when there was a risk indicator, 18 times greater when an ototoxic medication had been used, and 16.62 times greater when they stayed in ICUs.

Conclusion: the results show that knowing the indicators leads to considering the actions the team in charge should take.

Keywords: Neonatal Screening; Hearing Loss; Unified Health System 


\section{INTRODUCTION}

Hearing loss is a sensory deprivation that impairs language acquisition and speech development, although it can be minimized with an early diagnosis of the disability ${ }^{1}$. To detect it, the Joint Committee on Infant Hearing $(\mathrm{JCIH})$ has, since 1994, recommended neonatal hearing screening (NHS) to all newborns, as the presence of risk indicators for hearing loss (RIHL) can be identified in only $50 \%$ of the patients with hearing loss ${ }^{2,3}$.

In 2012, The Brazilian Ministry of Health issued the Neonatal Hearing Screening Care Guidelines to instruct the multiprofessional teams on child hearing health care - especially the NHS, which is to be conducted in two stages, the first one named test, and the second one, retest ${ }^{4}$.

In the first NHS stage, the professional surveys the clinical history of the newborn with identification of risks of hearing loss, due to the high number of abnormal results in the NHS and the late onset of hearing loss ${ }^{5,6}$. Then, if the newborn does not have RIHL, the first test to be used is the evoked otoacoustic emissions (OAE). If a failure occurs, that is, if a response is considered unsatisfactory, the same test is to be immediately repeated. If the failure persists, the brainstem auditory evoked potentials (automated or screening BAEP) examination is conducted still in this first stage ${ }^{4}$. On the other hand, in the newborn with RIHL, the first test must be conducted with the automated or screening BAEP because the prevalence of retrocochlear hearing losses, which cannot be identified with the OAE examination, is higher in this population ${ }^{4}$.

In the second stage, meant for the newborns with or without RIHL who had an unsatisfactory response in the test, the automated or screening BAEP is used up to 30 days after the last test. If the failure persists, they must be referred to the high-complexity service to confirm the diagnosis and provide the prosthesis ${ }^{4}$.

The recommendations for the NHS program methodology must be adjusted to each municipality's situation, as they may not meet the local health needs in such a diverse country as Brazil, with no loss to the identification, diagnosis, and intervention in children with hearing losses (whether congenital, permanent or with onset in the neonatal stage) beginning at 35 $\mathrm{dBHL}$.

Various other studies identified the RIHL and their associations with failure in the test and retest, specifically involving one or more maternities in a municipality 8,9 where the NHS was conducted. Nevertheless, this research aimed to show the result of a child hearing health program involving all the live newborns residing in this municipality.

Hence, the Hearing health Program of the municipality of Mogi Mirim, SP, Brazil, will present the dimension of the regional characteristics regarding the RIHL, and so favor the debate and implementation of health prevention and promotion actions in the municipal and inter-municipal child health care network, being a model to other teams.

It is important to follow the existing law to universally screen all the newborns residing in Mogi Mirim and get acquainted with the results of the child hearing health program in all its stages as a means to assess the service. Therefore, the objectives of this study were to describe the results of a neonatal hearing screening program and verify whether there is an association between failures in the examinations and the presence of RIHL in the three stages of the program: test, retest, and diagnosis.

\section{METHODS}

This research project was submitted to the Research Ethics Committee of the Universidade Estadual de Campinas (University of Campinas - UNICAMP), SP, Brazil, and approved on February 6, 2018, under evaluation report no. 2.487.739.

This one-cohort, observational, retrospective study encompasses all those enrolled in the Municipal Information System who had undergone the NHS between 2010 and 2016.

The municipality of Mogi Mirim implemented the speech-language-hearing service 33 years ago and now has 13 professionals working in the Neonatal Hearing Health Program in the primary and specialized health care.

The research was conducted with secondary data, obtained from a record book used to develop the first databank since the program began in the municipality, in 2009. It contains information on the newborn (present in the Live Birth Information System - SINASC, in Portuguese) ${ }^{10}$, their family's sociodemographic variables, clinical history with $\mathrm{RIHL}$, date and results of the examinations, and their referrals. In 2015, these data were entered into a spreadsheet and completed with information from the pregnant women record books and the hearing and language development monitoring program, to make it easier to analyze the variables and assess the program. 
In the first stage of the Neonatal Hearing Health Program, their clinical history was surveyed with the information on the RIHL in accordance with the Neonatal Hearing Screening Care Guidelines. The newborns were considered to have RIHL when they had at least one of the following indicators: family history of childhood-onset permanent deafness; consanguinity; neonatal intensive care unit (NICU) stay of more than 5 days; mechanical ventilation; ototoxic drug exposure; hyperbilirubinemia requiring exchange transfusion; severe perinatal anoxia; one-minute Apgar score of 0 to 4 , or five-minute Apgar score of 0 to 6 ; birth weight lower than 1,500 g; congenital infections; anomalies; genetic syndromes; neurodegenerative disorders; postnatal bacterial and/or viral infections; and traumatic brain injury ${ }^{4}$. However, neonatal convulsions, drug use, peri-intraventricular hemorrhage ${ }^{3}$, and preterm birth ${ }^{6}$ were indicators added for this study.

Then, all the newborns residing in the municipality were submitted to the transient otoacoustic emissions (TOAE) test with the Maico Ero-Scan device, which tests the frequencies from $1.5 \mathrm{kHz}$ to $4 \mathrm{kHz}$. The pass criteria were the signal-to-noise ratio higher than $4 \mathrm{dBSPL}$ at 1 $\mathrm{kHz}$ and higher than $6 \mathrm{dBSPL}$ at the other frequencies, in at least three of the frequencies assessed, including $4 \mathrm{kHz}$, as specified in the equipment used.

When the newborns had one or more RIHL, they were referred for the BAEP test. Following the municipality's guidelines, all the newborns were referred to the hearing and language development monitoring program, with a speech-language-hearing therapist in primary health care.

When the newborns failed the first test, they were referred for the retest, also conducted with the TOAE test; and when the failure result persisted, they were submitted to tympanometry and stapedius reflex test. If the result was not normal, the newborn was referred to an otorhinolaryngologist. The examination results were classified according to the audiological assessment instruction guide of the speech-language-hearing council system ${ }^{11}$.

If the acoustic immittance examination result was a type A tympanometric curve and the stapedius reflex was present, the newborn was referred for diagnosis with the BAEP test, using the equipment Pentetek Audtec - Brainstem potential, of the Audiscan system, which assesses with click stimulus the integrity of the auditory pathway at the frequencies of 2 to $4 \mathrm{kHz}$, as well as the specific frequency of $1000 \mathrm{~Hz}$. When the BAEP examination results were abnormal, the newborn was included in the municipality's rehabilitation program and referred to the Reference Hospital to confirm the diagnosis and provide the prosthesis.

Absolute frequency $(n)$ and percentages were used to describe the first and second stages of the NHS. To verify the association between the presence of RIHL and the TOAE failures in the test, retest, and hearing loss diagnosis, the odds ratio and confidence interval values were used, at the $0.5 \%$ significance level. The calculation considered the mean age when the retest was conducted.

\section{RESULTS}

A total of 7,800 newborns participated in the Neonatal Hearing Health Program of the Municipality of Mogi Mirim between 2010 and 2016.

Regarding the first stage of the test, 993 (12.73\%) out of the 7,800 participants had RIHL, whereas 155 $(15.60 \%)$ failed the first test. Of the 6,807 without RIHL, 351 (5.15\%) failed the first test. Altogether, 506 newborns were referred for the retest. The mean age in the first test was 17 days, while the retest was scheduled in a mean of 28 days after the first examination.

It is verified in Table 1 that the most frequent RIHL was prematurity $(n=571 ; 7.32 \%)$.

In the association measure between failure in the first TOAE examination and the RIHL, a participant's likelihood to fail the TOAE is associated with the following risks: craniofacial anomalies, birth weight lower than $1,500 \mathrm{~g}$, five-minute Apgar lower than 7 , drug use, perinatal anoxia, mechanic ventilation, NICU stay of more than 5 days, preterm birth, syndromes, congenital infection, ototoxic medication, and hyperbilirubinemia. 
Table 1. Distribution of the risk indicators for hearing loss at birth in the population studied, and association with failure in the first otoacoustic emissions test

\begin{tabular}{lcccc}
\hline Presence of RIHL & Frequency & Percentage & $\begin{array}{c}\text { OR association } \\
\text { measure }\end{array}$ & $\begin{array}{c}\text { CI } \\
\mathbf{( 9 5 \% )}\end{array}$ \\
\hline Preterm birth & 571 & 7.32 & 3.14 & $2.40-4.12^{\star *}$ \\
Ototoxic medication & 415 & 5.32 & 2.55 & $1.92-3.41^{* *}$ \\
ICU stay of more than 5 days & 326 & 4.17 & 3.08 & $2.26-4.20^{\star *}$ \\
Mechanical ventilation & 105 & 1.34 & 3.12 & $1.86-5.23^{\star *}$ \\
Family history & 93 & 1.19 & 1.44 & $0.62-3.32$ \\
Congenital infection (TORCH)* & 85 & 1.08 & 1.97 & $1.01-3.84^{\star *}$ \\
Birth weight <1,500 g & 70 & 0.89 & 7.88 & $4.75-13.07^{\star *}$ \\
Drug use & 69 & 0.88 & 5.36 & $3.10-9.24^{\star *}$ \\
Hyperbilirubinemia & 32 & 0.41 & 1.48 & $4.45-4.85^{\star *}$ \\
Perinatal anoxia & 33 & 0.42 & 4.27 & $1.75-10.41^{\star *}$ \\
Craniofacial anomalies & 25 & 0.32 & 37.16 & $15.34-90.05^{\star *}$ \\
Syndromes & 22 & 0.28 & 2.19 & $1.15-4.14^{* *}$ \\
5-minute Apgar < 7 & 13 & 0.16 & 6.59 & $2.02-21.47^{\star *}$ \\
Neonatal convulsions & 6 & 0.07 & 1.08 & $0.34-25.29$ \\
Peri-intraventricular hemorrhage & 2 & 0.02 & 7.37 & $0.67-81.47$ \\
Traumatic brain injury & 1 & 0.01 & 14.74 & $0.92-236.04$ \\
\hline
\end{tabular}

Source: Databank of the Neonatal Hearing Screening Program of the Municipality of Mogi Mirim

${ }^{*}$ RIHL-risk indicator for hearing loss, TORCH-Toxoplasmosis, Rubella, Cytomegalovirus, Herpes, and Syphilis, <lower than, Cl- confidence interval, OR- Odds Ratio

**association between the RIHL and failure in the first OAE test

In the retest stage, the newborns' mean age was 60 days. Of the $460(92.18 \%)$ that were retested, 348 (75.65\%) passed - 78 (22.41\%) with RIHL and 270 (77.58\%) without RIHL. Of these, 112 (24.35\%) failed the test again $-56(50 \%)$ of them with RIHL and 56 $(50 \%)$ without RIHL. In the study of the association of the presence of RIHL with failure in the test and retest, the likelihood of failure in the test was $3.40(95 \% \mathrm{Cl}$ :
2.78-4.15), while in the retest it was $3.46(95 \% \mathrm{Cl}$ : 2.21-5.42), which shows a similar likelihood in both examinations when RIHL is present.

Of the 7,800 newborns screened, 12 were diagnosed with hearing loss $-8(66.66 \%)$ with RIHL and 4 (33.34\%) without RIHL. The most frequent indicators were ototoxic medication $(75 \%)$ and NICU stay of more than 5 days $(62.50 \%)$, as seen in Table 3 .

Table 2. Association between the risk indicators for hearing loss and the results of the first Neonatal Hearing Screening test and the retest

\begin{tabular}{ccccc}
\hline NHS & Failed & Passed & OR association measure & CI (95\%) \\
\hline First OAE test & & & & \\
With RIHL & 155 & 838 & 3.40 & $2.78-4.15$ \\
Without RIHL & 351 & 6456 & & \\
\hline OAE retest & & & 3.46 & $2.21-5.42$ \\
With RIHL & 56 & 270 & & \\
Without RIHL & 56 &
\end{tabular}

Source: Databank of the Hearing Screening Program of the Municipality of Mogi Mirim

OAE- otoacoustic emissions, RIHL- risk indicators for hearing loss, Cl- confidence interval, OR- Odds Ratio 
Table 3. Description of the risk indicators for hearing loss in the participants with hearing loss

\begin{tabular}{|c|c|c|}
\hline Risk Indicators for Hearing Loss & Frequency & Percentage \\
\hline \multicolumn{3}{|l|}{ Family history } \\
\hline YES & 1 & 12.50 \\
\hline NO & 7 & 87.50 \\
\hline \multicolumn{3}{|l|}{ Ototoxic medication at birth } \\
\hline YES & 6 & 75.00 \\
\hline NO & 2 & 25.00 \\
\hline \multicolumn{3}{|l|}{ 5-minute Apgar $<7$} \\
\hline YES & 1 & 12.50 \\
\hline NO & 7 & 87.50 \\
\hline \multicolumn{3}{|l|}{ Drug use } \\
\hline YES & 1 & 12.50 \\
\hline NO & 7 & 87.50 \\
\hline \multicolumn{3}{|l|}{ NICU stay of more than 5 days } \\
\hline YES & 5 & 62.50 \\
\hline NO & 3 & 37.50 \\
\hline \multicolumn{3}{|l|}{ Preterm birth } \\
\hline YES & 3 & 37.50 \\
\hline NO & 5 & 62.50 \\
\hline \multicolumn{3}{|l|}{ Birth weight lower than $1,500 \mathrm{~g}$} \\
\hline YES & 3 & 37.50 \\
\hline NO & 5 & 62.50 \\
\hline \multicolumn{3}{|l|}{ Mechanical ventilation } \\
\hline YES & 3 & 37.50 \\
\hline NO & 5 & 62.50 \\
\hline \multicolumn{3}{|l|}{ Perinatal anoxia } \\
\hline YES & 2 & 25.00 \\
\hline NO & 6 & 75.00 \\
\hline \multicolumn{3}{|l|}{ Peri-intraventricular hemorrhage } \\
\hline YES & 1 & 12.50 \\
\hline NO & 7 & 87.50 \\
\hline
\end{tabular}

Source: Databank of the Hearing Screening Program of the Municipality of Mogi Mirim NICU- neonatal intensive care unit, < lower than, $g$ - grams

It was also observed that of the six $(75 \%)$ newborns with a history of ototoxic medication use, five had other RIHL, and all of them had in common the NICU stay of more than 5 days. However, one of the participants used ototoxic medication during childhood, due to a constant treatment of otitis media.

Of the eight participants with RIHL, two (25\%) had RIHL at birth - one had anoxia at birth, while the other was premature. However, this was not detected in the clinical history survey, which precedes the first OAE examination.
Of the 12 hearing losses, 10 were bilateral sensorineural and two were unilateral sensorineural.

Concerning the study of the association between the presence of RIHL at birth and diagnosis of permanent hearing loss, a participant with RIHL is 13 times more likely to present an abnormal result than one without RIHL. In the cases of ototoxic medication use and NICU stay of more than 5 days, the likelihood of having hearing loss is respectively 18 and 16.62 times greater in participants with RIHL than in those without it (Table 4). 
Table 4. Association between the presence of risk indicator for hearing loss at birth and diagnosis of permanent hearing loss

\begin{tabular}{lcccc}
\hline & With Hearing Loss & Without Hearing Loss & OR Association Measure & CI (95\%) \\
\hline With RIHL & 8 & 986 & 13.80 & $4.15-45.90$ \\
Without RIHL & 4 & 6802 & & \\
Medication use & 6 & 410 & 18.00 & $5.78-56.04$ \\
No medication use & 6 & 7378 & & \\
NICU stay & 5 & 321 & 16.62 & $5.54-52.64$ \\
No NICU stay & 7 & 7467 & & \\
\hline
\end{tabular}

Source: Databank of the Hearing Screening Program of the Municipality of Mogi Mirim

OAE- otoacoustic emissions, RIHL- risk indicators for hearing loss, NICU- neonatal intensive care unit, OR - Odds Ratio, Cl- confidence interval

\section{DISCUSSION}

The Brazilian guidelines and the international literature recommend NHS before hospital discharge to ensure the adherence of newborns and the universality of the screening, as hospital follow-up visits are known to pose social-related challenges ${ }^{4,5}$. On the other hand, in the Brazilian reality, the outpatient center is a more feasible model, due to both the country's sociodemographic differences and the lack of human resources and equipment needed in maternities ${ }^{12,13}$.

The municipality of Mogi Mirim decided on the Outpatient Neonatal Hearing Health Program because when it was implemented, in 2009, there were not enough human resources to offer this service at the hospital and the hospital health care did not belong to the municipal health care network. To implement the Program, the speech-language-hearing team counted with the cooperation of social control and municipal administrators, who made the financial resources available to buy equipment and train the human resources to perform the examinations. It is important to highlight that the Program was developed with the involvement of professionals from all health care levels, including primary, specialized, and hospital health care. The Neonatal Hearing Health Program of the municipality of Mogi Mirim is a reference to all live newborns who reside there, regardless of the place and municipality where they were born. In some cases, it is a reference to other municipalities as well, belonging to the Sistema Único de Saúde (Brazilian Public Health Care System), health insurances, or private network.

Of the population studied, in the first NHS stage, after the RIHL was surveyed, 993 participants (12.30\%) presented RIHL. This result is similar to that of Brazilian studies carried out in Belo Horizonte and Curitiba, as well as in another country, Poland, with $13 \%, 12 \%$, and $11.3 \%$, respectively. On the other hand, it was higher than the guidelines of the Ministry of Health, which is $10 \%$, 13-15.

It was observed in this study that the most frequent RIHL was prematurity, in $7.30 \%$ of the participants. This result is similar to that of research conducted in a Family Health Strategy service, in which $6 \%$ of the newborns had this indicator ${ }^{12}$. However, in another piece of research from the municipality of Botucatu, prematurity had a higher value, in $24 \%$ of the newborns - although the sample's comprising only participants with RIHL may have influenced this result ${ }^{16}$.

In the first stage of the test, the examination was conducted at the mean age of 17 days. In it, 5.15\% failed, and all of them were referred for the retest. Other studies had similar findings, with results of $6 \%, 7 \%$, and $6 \%$ for the failures - which are above what has been proposed by the quality indicators ${ }^{14,13,17}$.

In research carried out in Luxembourg, it was observed that the newborn's age can influence their passing or not the test and that $95 \%$ had a satisfactory result when submitted to the NHS between the fourth and fifth day of life. Hence, the percentage of newborn failure before the hospital discharge is higher, which reaffirms the importance of performing the NHS in the first 30 days of life. Consequently, the likelihood of failure is reduced, as well as the referrals for retest and diagnosis ${ }^{18}$. Therefore, a Program that takes place at the outpatient level, as is the case in this research, can have better indicators in terms of the percentage of failures in the first test than in hospital Programs.

In the present study, the participants underwent the retest having it scheduled in a mean of 28 days after the first TOAE examination. This complies with the instructions by the Multiprofessional Hearing Health Committee because it reduces the occurrence of false positives due to the presence of vernix caseosa in the outer ear in the first days of life ${ }^{3}$. Nevertheless, $24.35 \%$ of the participants failed the retest - a higher index than 
the one found in a previous study, which was $10.96 \%{ }^{19}$. However, the mean age in the retest was 60 days, and the factors that may have contributed to this result were absence in the scheduling, presence of vernix in the external acoustic meatus, and middle ear infections.

There was a $92.18 \%$ retest adherence, a higher value than those of studieson outpatient programs conducted in Brazilian cities, Belo Horizonte and Campinas, whose percentages were $71.9 \%$ and $85 \%$, respectively ${ }^{12,13}$. As for the comparison with research on programs in hospital settings (e.g., those from the municipalities of Botucatu and Sobradinho), the retest adherence was $70 \%$ and $71.1 \%$, respectively - and it is interesting to point out that this stage was conducted after the discharge ${ }^{16,19}$. These findings comply with the $\mathrm{JICH}$ instructions to two-stage screening programs, that the referral for the retest must encompass $5 \%$ to $20 \%$ of all the participants assessed, and the retest attendance rate in programs that have been implemented for longer must exceed $90 \%{ }^{5}$.

The factors that can contribute to this important datum - i.e., the significant program adherence - may be related to the instructions given to the pregnant women regarding the importance of the NHS, the possibility of a retest, and the involvement of a whole team of professionals. These can include the speechlanguage-hearing therapist (responsible for the test and retest), the social worker (who is constantly and actively seeking the patients), the involvement of the primary care health professionals (especially the community health agents), the speech-language-hearing therapists, and even the receptionists in the community health centers. However, there are programs with better results, such as that of the municipality of Batatais, a city in inland São Paulo State, with a 95.07\% adherence ${ }^{17}$. Hence, making sure the families are aware of the importance of the NHS and the consequences of hearing loss to the children's development is essential to the adherence in all the stages of an NHS program ${ }^{20}$.

Another important factor to the retest adherence, unlike other published studies, especially comparing with hospital programs, is that all the stages happen in the same place. As a result, a connection is developed with the families and the retest is scheduled by the speech-language-hearing therapist responsible for the first test on the same day the failure occurs, which is when they are told about the importance of attending the retest.

The study of the association between the presence of RIHL and failure in the first TOAE examination in the test and retest revealed a similarity in which the group of children with RIHL was respectively 3.40 and 3.46 times more likely to fail than in the group with no RIHL. The study conducted in Belo Horizonte found that the group of children with RIHL was 2.4 times more likely to fail the examination than the group with no RIHL without a statistically significant difference between the retest groups ${ }^{13}$.

Concerning the association of failure in the OAE with the RIHL, neither did the study by Oliveira et al. find an association of failure in the OAE with family history and congenital infections. However, there are similar data to those of the present study, as they also found an association with the occurrence of craniofacial malformation, birth weight lower than $1,500 \mathrm{~g}$, hyperbilirubinemia, mechanical ventilation, five-minute Apgar lower than 7 , and syndromes ${ }^{21}$.

As for the diagnostic findings, 12 out of the 7,800 participants were diagnosed with hearing loss - eight of whom (66.66\%) had RIHL at birth, and four (33.34\%) did not have it. This shows the importance of a universal $\mathrm{NHS}$, as instructed in the international and national literature ${ }^{3.5}$. Similar data were found in a study carried out in India, in which the highest percentage of hearing loss occurred among the participants with RIHL, reinforcing the conclusion about the importance of performing hearing assessments in all the newborns ${ }^{22}$.

Of the eight participants with RIHL diagnosed with hearing loss, in six (75\%) the most frequent RIHL were the ototoxic medication (75\%) (of whom, five had this $\mathrm{RIHL}$ at birth) and NICU stay of more than 5 days. These data are similar to those of a study conducted at a university hospital with infants coming from the NICU, in whom the ototoxic medication was the most frequent RIHL $(73 \%)^{23}$.

A participant in this study took ototoxic medication during childhood to treat recurrent otitis. Various authors point out that the strategies to prevent hearing loss must include goals to diminish middle ear infections (such as otitis), ototoxic antibiotic use during the fetal and neonatal periods and childhood, and NICU room noise, besides instructing the parents about the risk of progressive or late hearing loss. Hence, the risk of the cochlear lesion is prevented or minimized ${ }^{24,25}$.

It is important to highlight that this participant with RIHL during childhood participated in the child development monitoring program in the primary health care with the reference speech-language-hearing therapist of that area. Also, it was through the interface with the specialized attention that the hearing loss 
was diagnosed. These data show the importance of monitoring the development of children regardless of the presence of $\mathrm{RIHL}$ - as it is the practice in the municipality where this research was conducted, although the Neonatal Hearing Screening Care Guidelines of the Ministry of Health only instruct the monitoring of children with RIHL ${ }^{4}$.

Of the eight participants with RIHL, two (25\%) had $\mathrm{RIHL}$ at birth - the indicators were anoxia at birth and prematurity, which were not detected in the clinical history survey, which precedes the first OAE examination. In these two cases specifically, it is important to highlight that the primary health care professionals observed a delay in the infants' development, and they were then referred to specialized health care professionals. Both health care levels surveyed the RIHL, which were not observed at birth.

Given these results, the professionals of all health care levels involved in child health care must give more attention when filling out and verifying the personal child health record in each consultation. It is also necessary to consider a new approach to listening to the clinical history during prenatal, natal, and postnatal periods, and throughout their childhood.

Ten (83.33\%) out of the 12 hearing losses were bilateral sensorineural, while two (16.67\%) were unilateral sensorineural. A study conducted in the whole region of Lazio, in Italy, found data similar to those of the present study, with a higher percentage of bilateral hearing losses: $60 \%$ of the children, against $40 \%$ with unilateral ones ${ }^{26}$. In another study with 37 children 0 to 11 years and 11 months, $73 \%$ of the children were diagnosed with bilateral hearing losses, while $27 \%$ had unilateral ones ${ }^{27}$. On the other hand, in a study conducted in an African archipelago, 100\% of the participants had bilateral hearing losses, all of them with $\mathrm{RIHL}{ }^{28}$. These are relevant data because they show the importance of considering the regional differences when defining the use of neonatal hearing screening protocols and team instructions regarding the results found ${ }^{29}$.

Concerning the study of the association of the presence of RIHL at birth with the diagnosis of permanent hearing loss, the data in this paper are different from those of a previous study conducted at a hospital in Minas Gerais, in which a participant with $\mathrm{RIHL}$ was eight times more likely to have a hearing loss than those without RIHL. Ototoxic medication use and NICU stay of more than 5 days had no statistical significance to hearing loss ${ }^{30}$. Thus, the importance of the study in question is justified, as it encompasses the whole municipality, which considers the regional differences and cooperates in planning according to the local needs.

It was possible to carry out this research because the Program has always been concerned with implementing a single databank covering the whole municipality, following the instructions in the national and international literature ${ }^{3-5}$.

It is also important to highlight that the information on the RIHL and the newborns' age at the first test and retest of those that were not submitted to the first OAE examination in the speech-language-hearing service at the Department of Specialties of Mogi Mirim are included in the databank of the Program after the administration or regulation of the Program actively seeks them, as provided in the municipal law. The tools used in actively seeking them are phone calls, locating the family in the primary health care, or e-mails sent to other Programs in the neighboring municipality.

\section{CONCLUSION}

The present study showed that there was a similar likelihood of failing the first examination and the retest with OAE when the infant had RIHL. Therefore, it restates the importance of surveying the RIHL at birth.

The most frequent RIHL were ototoxic medication use and NICU stay for more than 5 days - although the likelihood of failing the first OAE examination occurred along with $11 \mathrm{RIHL}$.

Infants were 13 times more likely to be diagnosed with hearing loss when they had RIHL, 18 times more likely when ototoxic medication had been used, and 16.62 times more likely when they had stayed in the NICU for more than 5 days.

The data reinforce the importance of universal NHS and of knowing the RIHL to make decisions and changes regarding the health prevention and promotion actions, to monitor and follow up the children's development and the hearing health programs and protocols.

\section{REFERENCES}

1. Bevilacqua MC, Formigoni GMP. Audiologia educacional: uma opção terapêutica para a criança deficiente auditiva. $3^{\underline{a}}$ ed. Carapicuiba, SP: Pró-Fono; 1998. 
2. Northern JL, Downs MP. Desenvolvimento do comportamento auditivo. In: Northern JL, Downs MP, editors. Audição em crianças. 3a ed. São Paulo: Manole; 1989. p.101-41.

3. Lewis DR, Marone SAM, Mendes BCA, Cruz OLM, Nóbrega M. Comitê multiprofissional em saúde auditiva: COMUSA. Braz J Otorhinolaryngol. 2010;76(1):121-8.

4. Brasil. Ministério da Saúde. Secretaria de Atenção à Saúde. Departamento de Ações Programáticas Estratégicas. Diretrizes de Atenção da Triagem Auditiva Neonatal / Ministério da Saúde, Secretaria de Atenção à Saúde, Departamento de Ações Programáticas Estratégicas e Departamento de Atenção Especializada. Brasília: Ministério da Saúde, 2012. 32 p.: il.

5. Joint Committee on Infant Hearing. Year 2019 Position Statement: Principles and Guidelines for Early Hearing Detection and Intervention Programs. J Early Hear Detect Interv. 2019;4(2):1-44.

6. Azevedo MF. Avaliação audiológica infantil. In: Marchesan IQ, Justino $\mathrm{H}$, Tomé MC, editors. Tratado de especialidades em fonoaudiologia. São Paulo: Guanabara Koogan; 2014. p. 924-9.

7. Lewis DR, Chapchap MJ. Triagem auditiva neonatal universal: boas práticas atuais. In: Marchesan IQ, Silva HJ, Tomé MC, editors. Tratado das especialidades em fonoaudiologia. São Paulo: Guanabara Koogan; 2014. p. 867-77.

8. Vernier LS, Castelli CTR, Rothermel SS, Paniz TC, Zanini C, Levandowski DC. Triagem auditiva neonatal em hospital da rede cegonha. Rev Bras Promoç Saúde. 2019;32:8965.

9. Rezende ALF, Resende LM, Carvalho EAA, Avan $P$, Carvalho SAC. Evaluation of children with risk indicators for hearing loss in a Newborn Hearing Screening Reference Service. Distúrb. Comun. 2019;31(4):630-40.

10. Ministério da Saúde. Brasil. SINASC-DATASUS. Sistema de Informação de Nascidos Vivos. [Accessed on 2018 January 15]. Available at: http://www2.datasus.gov.br/DATASUS/index. php?area $=060702$.

11. Sistema de Conselhos de Fonoaudiologia. Guia de orientação na avaliação audiológica básica. 2017. [Accessed on 2019 December 28]. Available at: https://www.fonoaudiologia.org.br/cffa/wp-content/ uploads/2013/07/Manual-de-Audiologia.pdf.
12. Lima MCMP, Rossi TRF, Françozo MFC, CollelaSantos MF, Correa CR. Analysis of neonatal hearing screening program performed on an outpatient basis. Int $\mathrm{J}$ Pediatric Otorhinolaryngol. 2015;79(12):2227-33.

13. Januário GC, Lemos SMA, de Lima Friche AA, Alves CR. Quality indicators in a newborn hearing screening service. Braz J Otorhinolaryngol. 2015;81(3):255-63.

14. Sabbarg JC, Lacerda ABM. Neonatal hearing screening in primary health care and family health care. CoDAS. 2017;29(4):e20160102.

15. Wroblewska-Seniuk K, Greczka G, Dabrowski P, Szyfter W, Mazela J. The results of newborn hearing screening by means of transient otoacoustic emissions - has anything changed over 10 years? Int J Pediatric Otorhinolaryngol. 2017;96(5):4-10.

16. Silva DPC, Lopez PS, Ribeiro GE, Luna MOM, Lyra JC, Montovani JC. The importance of retesting the hearing screening as an indicator of the real early hearing disorder. Braz $\mathrm{J}$ Otorhinolaryngol. 2015;81(4):363-7.

17. Bertoldi P, Manfredi A, Mitre E. Analysis of the results of newborn hearing screening in the city of Batatais. Medicina Ribeirão Preto. 2017;50(3):150-7.

18. Panosetti E, Shi BX, Eloy JP, Orband D, Rasque E. Oto-émissions provoquées à la naissance: l'expérience luxembourgeoise. Arch Pediatr. 1999;6(2):353-5.

19. Marinho ACA, Pereira ECS, Torres KKC, Miranda AM, Ledesma ALL. Evaluation of newborn hearing screening program. Rev Saude Publica. 2020;54(1):44-51.

20. Archana RS, Reethu MS, Vibha V. Is awareness of infant hearing screening in India still in its infancy. A Survey. Glob J Otolaryngol. 2019;19(5):94-8.

21. Oliveira CS, Santiago DB, Valente JSP, Borja ALVF, Bernardi APA. Prevalence of risk indices for hearing loss in 'failure' results of newborn hearing screening. Rev. CEFAC. 2015;17(3):827-35.

22. James M, Kumar P, Ninan PJ. A study on prevalence and risk factors of hearing impairment among newborns. Int $\mathrm{J}$ of Contemp Pediatr. 2018;5(2):304-9.

23. Rechia IC, Liberalesso KP, Angst OVM, Garcia FD, Garcia MV, Biaggio EPV. Intensive care unit: results of the Newborn Hearing Screening. Braz J Otorhinolaryngol. 2016;82(1):76-81. 
24. World Health Organization. Childhood Hearing Loss: Strategies for prevention and care. World Health Organization: Geneva, Switzerland. 2016;1-28.

25. Garinis AC, Kemph A, Tharpe AM, Weitkamp JH, McEvoy $C$, Peter $S$ et al. Monitoring neonates for ototoxicity. Int J Audiol. 2018;57(4):54-61.

26. Turchetta R, Conti G, Marsella P, Orlando MP, Picciotti PM, Frezza $S$ et al. Universal newborn hearing screening in the Lazio region, Italy. Ital $\mathrm{J}$ Pediatr. 2018;44(1):104.

27. Gouveia FN, Corteletti LCBJ, Silva BCS, Araujo EJ, Amantini RCB, Oliveira EB et al. Unilateral and asymmetric hearing loss in childhood. CoDAS. 2020;32(1):e20180280.

28. Abraham ZS, Alawy K, Massawe ER, Ntunaguzi D, Kahinga AA, Mapondella KB. Prevalence of hearing loss and associated factors among neonates in Zanzibar. Med J Zambia. 2018;45(2):98-105.

29. Ribeiro GE, Montavani JC, Silva DPC. Neonatal hearing screening: the importance of the study of risk indicators for hearing loss. J Otolarynbgolent Res. 2017;8(3):00244.

30. Barboza ACS, Resende LM, Ferreira DBC, Lapertosa CZL, Carvalho SAS. Correlation between hearing loss and risk indicators in a neonatal hearing screening reference service. Audiol. Commun. Res. 2013;18(4):285-92. 